\title{
Peroral endoscopic myotomy (POEM) for achalasia after Roux-en-Y gastric bypass
}

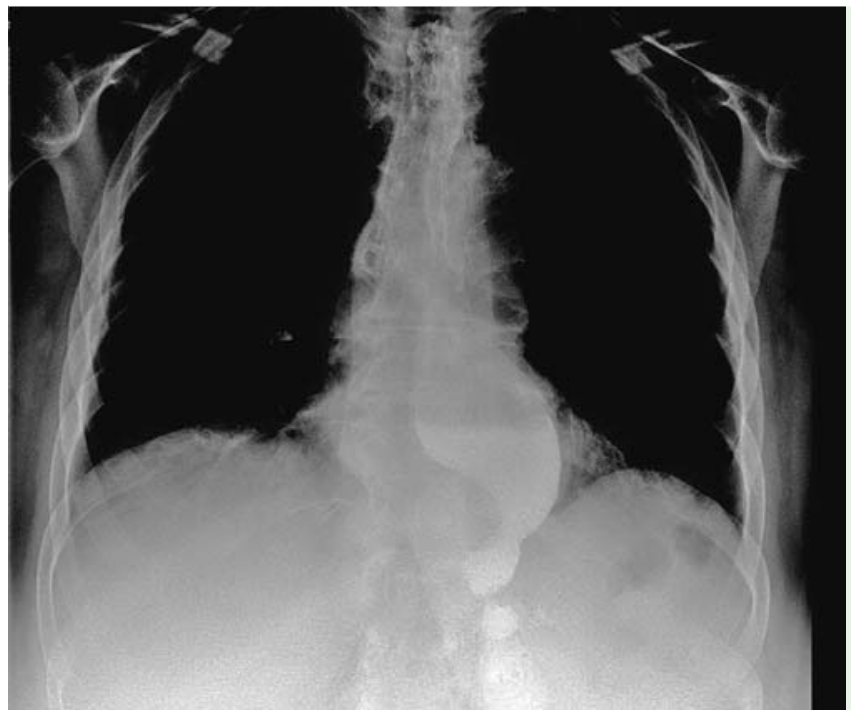

Fig. 1 Timed barium esophagram showing dilated distal esophagus with delayed emptying of esophageal contents, and tapering at the lower esophageal sphincter (LES).

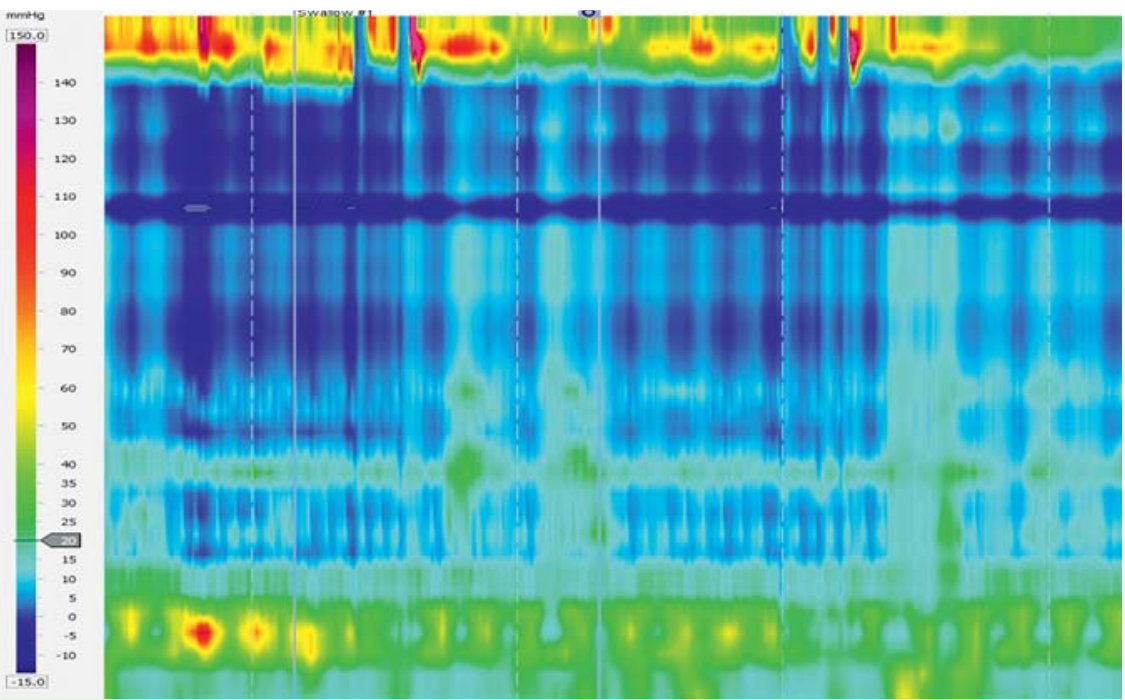

Fig.2 High-resolution esophageal manometry demonstrating esophageal aperistalsis, and impaired lower esophageal sphincter (LES) relaxation.

Achalasia is a relatively rare esophageal motility disorder which has been reported to have an incidence of $1 \%$ in the morbidly obese population $[1,2]$. In line with the increase in number of severely obese individuals and concomitant rise in weight-loss procedures, post-bariatric surgery patients with symptomatic achalasia pose a surgical challenge. We present a patient with achalasia and RouX-en-Y gastric bypass (RYGB) successfully treated with peroral endoscopic myotomy (POEM).
A 64-year-old woman with RYGB presented with a 2-year history of progressive dysphagia, regurgitation, and a baseline Eckardt score of 4. Esophagogastroduodenoscopy (EGD) revealed a dilated esophagus, a gastric pouch without lesions, and a wide gastrojejunostomy. Esophagography showed delayed esophageal emptying and narrowing at the lower esophageal sphincter (LES) ( Fig. 1). High resolution manometry demonstrated esophageal aperistalsis and impaired LES relaxation ( Fig.2). We performed POEM as previously described $[3,4]$, with selective

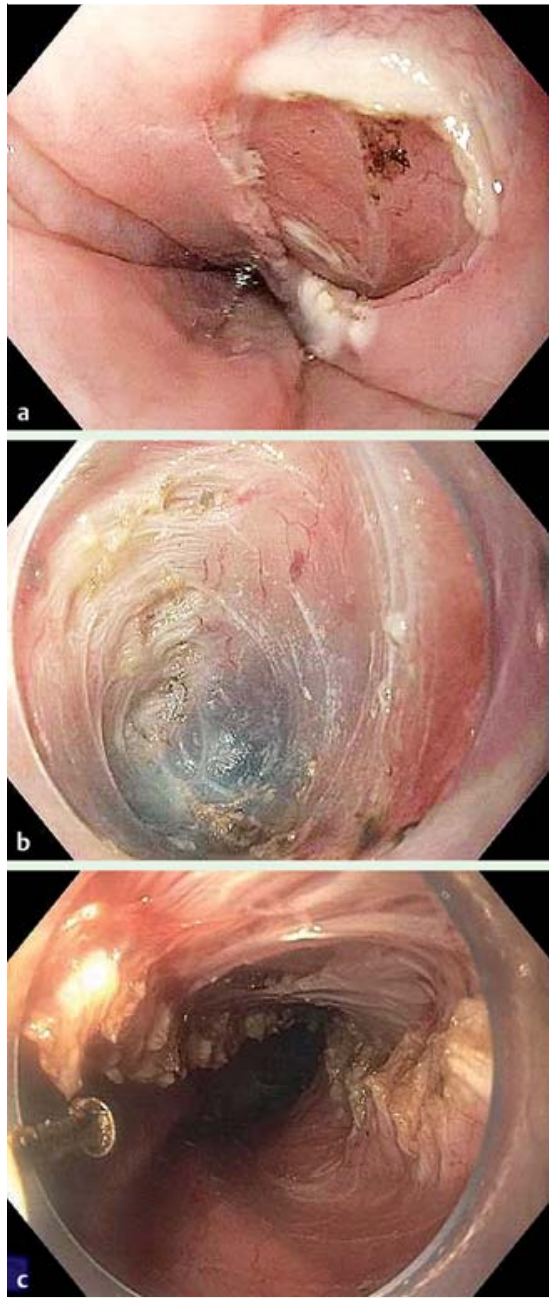

Fig. 3 Peroral endoscopic myotomy (POEM). a Mucosal incision site in the mid-esophagus. b Endoscopic view of submucosal tunnel. c Selective myotomy of circular muscle fibers.

myotomy of the circular muscle fibers and advancing $4 \mathrm{~cm}$ into the gastric pouch (total myotomy length of $14 \mathrm{~cm}$ ) ( Fig.3). Esophagography on postoperative day 1 revealed no leak of oral contrast with adequate passage into the gastric pouch and beyond the gastrojejunostomy ( $\bullet$ Fig.4). The patient's dysphagia and regurgitation had resolved at follow-up 5 weeks postoperatively, with an Eckardt score of 0 .

Laparoscopic Heller's myotomy (LHM) and pneumatic balloon dilation are historically considered the standard of care for achalasia [5]. However, management of post-bariatric surgery patients with achalasia is often complicated by exten- 


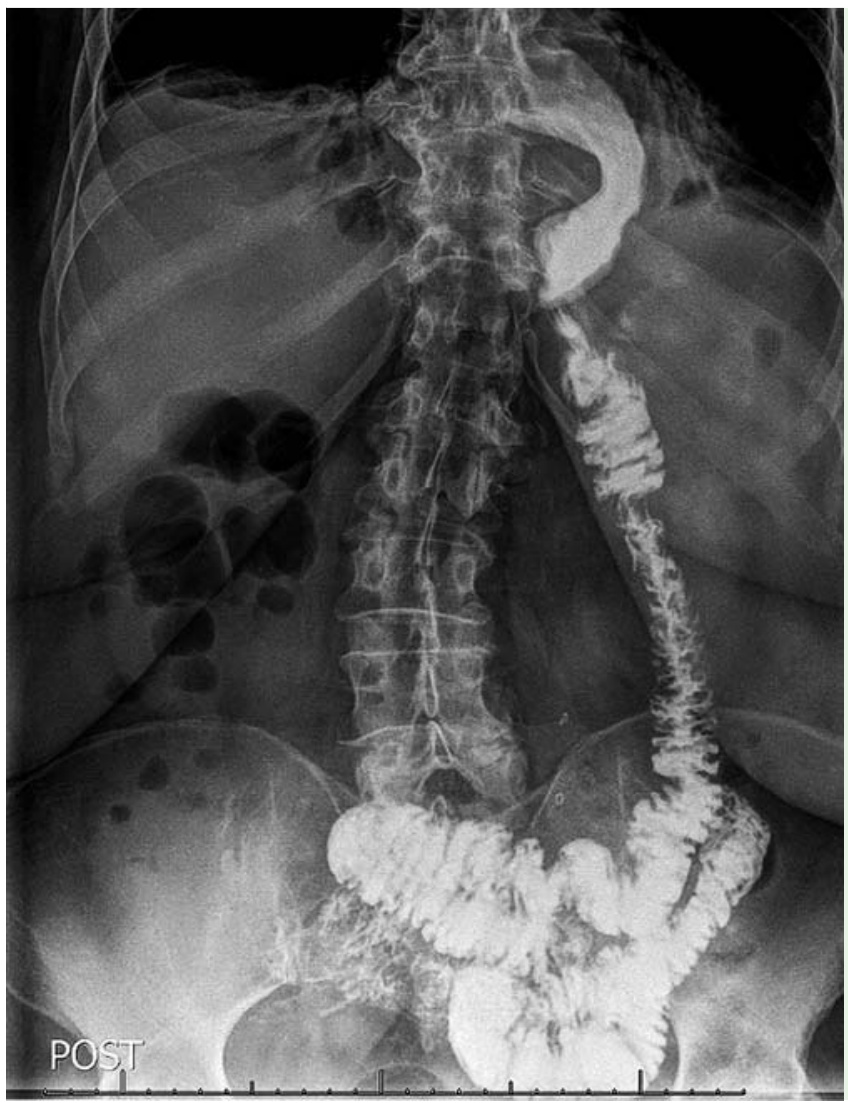

sive adhesions and altered anatomy $[6,7]$. The potential advantages of POEM include minimal invasiveness, allowance of a longer esophageal myotomy if required, and that it can be more easily revisited without requiring open surgical access. In this study, we demonstrate that POEM was feasible, safe, and effective for symptomatic relief in an achalasia patient with RYGB. POEM should be included as a potential treatment option for achalasia patients with previous bariatric surgeries.
Fig. 4 Barium esophagram on postoperative day 1 revealing satisfactory emptying of oral contrast into the gastric pouch and beyond the gastrojejunostomy.

\section{References}

1 Koppman JS, Poggi L, Szomstein $S$ et al. Esophageal motility disorders in the morbidly obese population. Surg Endosc 2007; 21: $761-764$

2 Almogy G, Anthone GJ, Crookes PF. Achalasia in the context of morbid obesity: a rare but important association. Obes Surg 2003; 13: 896-900

3 Inoue H, Minami H, Kobayashi Yet al. Peroral endoscopic myotomy (POEM) for esophageal achalasia. Endoscopy 2010; 42: 265 271

4 Yang D, Wagh MS. Peroral endoscopic myotomy (POEM) for the treatment of achalasia: an analysis. Diagn Therapeut Endosc 2013. doi: 10.1155/2013/389596 [Epub ahead of print]

5 Boeckxstaens GE, Annese V, des Varannes SB et al. Pneumatic dilation versus laparoscopic Heller's myotomy for idiopathic achalasia. N Engl J Med 2011; 364: 1807-1816

6 Ramos AC, Murakami A, Lanzarini EG et al. Achalasia and laparoscopic gastric bypass. Surg Obes Relat Dis 2009; 5: 132-134

7 Chapman $R$, Rotundo A, Carter $N$ et al. Laparoscopic Heller's myotomy for achalasia after gastric bypass: A case report. Int J Surg Case Rep 2013; 4: 396-398

\section{Bibliography}

Dol http://dx.doi.org/

10.1055/s-0033-1359140

Endoscopy 2014; 46: E11-E12

(c) Georg Thieme Verlag KG

Stuttgart · New York

ISSN 0013-726X

Competing interests: None of the authors have relevant disclosures or conflict of interest to declare related to this study.

\section{Dennis Yang, Peter V. Draganov}

Division of Gastroenterology, University of Florida, Gainesville, Florida

\section{Corresponding author \\ Peter V. Draganov, MD}

Division of Gastroenterology

University of Florida

1600 SW Archer Road, Room HD 602

Gainesville, FL 32610

USA

Fax: +1-352-392-3618

peter.draganov@medicine.ufl.edu 